\title{
Practices and Cases in e-Education
}

\author{
M. Saravana Kumar and N. V. Jayaraman
}

\begin{abstract}
Education is now under a mystified stage of identifying what category of approach that may be adopted for more employability option. The institutions should follow typical knowledge based education or more skill based workability based education. Getting employment after professional education is a must for the young graduates. The paper discusses various issues and challenges related to IT application in soft skill training. The students overall skills have to be increased in tough environment to achieve success. But most of the students from rural areas have not been able to access to training modules embedded with IT. In the first phase of the IT enabled soft skill training program, 5000 students was undertaken with funding from ministry of Information Technology, Government of India in improving the overall skill development of engineering students. The various factors of soft skills are studied for the future enables of IT in development of the students.
\end{abstract}

Index Term-Soft skills, e-tutoring, multimedia, simulation.

\section{INTRODUCTION}

Computer-Supported learning has received increased attention from Educators and Researchers as a result of the convergence of technology and economics (Chatterji, 2000). In technology, rapid advances in telecommunications are linking not only individual students with their peers and instructors, but also entire schools with their counterparts across the globe. These changes are fueled by the increased affordability of personal computers and the explosive growth of computer-mediated communications that are responsible for the larger number of computers in households, campuses and offices.

Computer-Supported learning options represent an opportunity and a threat (Twigg, 2000). It can potentially attract more students or increase class sizes by using the technology. But they are competing with their own traditional offerings as well as other educational institutions and even commercial learning companies. Increased competitive pressures along with the availability of technology are producing a shift from classroom-based education to computer-supported learning. These technological and economic trends, the lifelong learning and continuous education movements have moved responsibility for learning from the professor/instructor to the student/worker (Farrington, 1999)

Manuscript received February 9, 2012; revised March 20, 2012.

M. S. Kumar is with Associate Professor, Dean (Academics) and Programmme Director-IT Soft Skills Project, Anna University of Technology, Coimbatore.

N. V. Jayaraman is with Director-IT Soft Skills Project, Anna University of Technology, Coimbatore.

\section{REVIEW OF LITERATURE}

\section{A. Information Technology (IT)}

According to Meadow croft (2006), IT is the technology used to store, manipulate, distribute or create information. It is also the tool that we use to perform calculations, to store, and manipulate text, and to communicate. Marzelle quoted in UNDP (2002) states that, IT are both traditional (such as radio, television, dance, drama, print and fax) and new devices such as the Internet, the World Wide Web, Electronic mail, Teleconferencing, and Multimedia tools such as CD-ROMS, hypertext, iPod, virtual classroom etc.--

Information Technology (IT) are electronic and nonelectronic technologies, infrastructure, systems, and services used to publish, store, retrieve, and transmit information, to communicate ideas, and to generate knowledge (Mejiuni and Obilade, 2006).World Bank(2002), defines IT as the convergence of activities that facilitates capturing, processing, transmission and display of information through digital electronic devices, telecommunication, internet, world wide web, virtual realties and cyber space. According to this School of Thought, the potential of IT in providing equitable access to education is a fact that is widely accepted by all. It has provided viable platform for generation, adoption and exploitation of knowledge through open and distance education. Information Technology perceived in this way can give a boost to open and distance learning. There is no denying the importance of IT to open and distance learning. IT guarantees the absolute access of the individual to education.

\section{B. Teaching/Learning Model}

There are two opposite but complementary models of the teaching/ learning process. Teaching can be one-way "objectivist" transmission of knowledge from the professor to the students in which each student learns individually (Bouton \& Garth, 1983). Alternatively, teaching can be a communal experience where knowledge is created through constructive dialogue and group discussion, in which the professor facilitates the process.

These different approaches make different demands on technology. The instructive model of learning (objectivist) assumes that there is a single objective reality and the goal of learning is to understand that reality. In this instructorcentered model, the professor is someone who has attained a high degree of understanding and knowledge in the field and the student is a passive recipient of instruction.

Aungles (1991) agrees that the role of teachers will change with the advances of information technology but suggests a more pragmatic role. Students do not lack information, but rather the time to find, analyze, understand and apply information (Simon, 2002). A teacher's role is therefore to help students develop skills in order to 
determine how to find, analyzed and interprets information. Wharton (1994) summarizes the main elements of this shift and suggests that the role of teaching in information technology enhanced learning environments is to develop a student-centered learning environment, demonstrate effective information management strategies, stimulate active learning, and facilitate group learning activities. More than just a tool, information technology is increasingly becoming the content of education, as educators seek to teach students how to use the technology that is available (Hill, 1999)

\section{E-Learning and its Impact on Teachers}

The networked environment has an impact on the eteachers. The implementation of e-teaching is as challenging as the teachers have to adopt the teaching methodologies of the dot.com age which are new to them. They will work in an environment in which they have never been learners and may have had few first-hand experiences. They will have the opportunity to be pioneers in their own right as they set sail and also have the chance to re-examine what it means to be a teacher.

\section{The fear of e-Teaching}

The level of internal motivation to utilise ICT and to consider new and different teaching options was found to be an essential factor in research by Goodwin et al. (1993), Hirschbuhl (1994) and Wolcott (1997) in tertiary education settings. A positive attitude toward the use of ICT was a strong indicator of whether a teacher might consider eteaching. One of the major barriers to e-teaching identified by Hirschbuhl was the fear of unknown when they are subjected to teach the subjects by using the ICT enabled teaching tools. At Emporia State University, Clay and Grover (1995) found that the fear centred on staff feelings of having little or no preparation or support to teach in this new way. This fear was consistent with the findings of a study of staff integration of technology into their teaching by Munson, Poage, Conners and Evavold (1994). Some of the fears expressed are like fear of looking foolish, fear of asking for help, fear of not 'catching on' quickly enough, and fear of not being able to be effective with the technology in instructional settings. It was important for us to note that these fears were self-imposed and self-generated, but were not real.

Rutherford and Grana (p. 765) (1995) also focused their research on academic staff fear in the face of technology. They identified nine areas that could prevent staff from making changes that would enable them to integrate technology into their teaching:

\section{Fear of change}

2. Fear of time commitment

3. Fear of appearing incompetent

4. Fear of techno lingo

5. Fear of techno failure

6. Fear of not knowing where to start

7. Fear of being married to bad choices

8. Fear of having to move backward to go forward

9. Fear of rejection or reprisals (p. 83) lack of support, and an unwillingness to experiment with innovation all impact on the move to e-teaching.It is important that the concerns are acknowledged and addressed if progress toward e-teaching is to be made for many teachers.

\section{E. Predictors of Success (E-Teaching)}

Contrasting this notion of fear, Kaye (1989) indicated four predictors of success when using computers to teach students at a distance:

○ some prior familiarity with the technology - at least at the level of word-processing, and in the use of electronic mail

o an interest in the educational potential of networking and CMC [computer mediated communication]

○ a commitment to the values of group work and cooperative learning

○ sufficient time, not only actual on-line time, but, more importantly, the time to consider students' contributions and react to them appropriately. (p. 15)

\section{F. The Preconceptions about e-Learning}

Rosenberg (2001) described how e-learning "refers to the use of Internet technologies to deliver a broad array of solutions that enhance knowledge and performance" (p. 28). To suggest that e-learning is about having something "delivered" to the student infers a less interactive environment and one where the student may well spend considerable time teaching themselves! However having access to vast amounts of information online is to deny the importance of social interaction and the communication and interaction that take place as part of the practice of teaching. Networking is not just about information and linked technologies, it is something that people can engage in most effectively online and provide one of the real strengths of elearning.

Despite the wealth of available information available on the Internet this is not the essence of e-education. Andrew Feenberg (1999) believed that the primitive technologies that were used for asynchronous, text-based human interaction in the early days of the Internet are still some of the most exciting activities that take place even today. This view was shared by Palloff and Pratt (2001) who reported that student evaluations of e-learning highlighted their ability to engage with their peers in asynchronous discussion. While the Internet does allow for the transmission of video images to simulate a face-to-face interaction this relies on synchronous activity, not something all users will desire. Research has yet to validate this mode of interaction over other less time and cost intensive asynchronous options.

We do e-learning an injustice if it is simply regarded as something to emulate what is currently happening in classrooms or to suggest that it is an "alternative" to current classroom activity. Nothing could be further from the truth when there is an interactive environment facilitated by an eteacher who sees the potential to utilise the learning environments which best meet the needs of her/his students.

The issues of a lack of knowledge about ICT, a perceived 


\section{G. E-Learning is not about Screens and ICT}

Involvement in e-learning is not going to mean that teachers will spend hours sitting in front of computer screens any more than there is an expectation that their students will be doing the same. To focus on this perspective is to assume that the technology is the vehicle for all eactivity and nothing could be further from the truth. Elearning is not going to replace libraries, friends, colleagues and many of the existing social networks that contribute to a satisfying learning and teaching experience. In fact many of these will be enhanced by the ability of the teacher to access them in different ways. This is not an either/or type of learning environment but one where the Internet can be used for the things that cannot be achieved in any other way. The flexibility, availability and adaptability of the Internet environment must serve the needs of both e-teachers and elearners.

\section{H. A comparison of some Aspects of Conventional} Learning and e-Learning Are Shown In TABLE I Below:

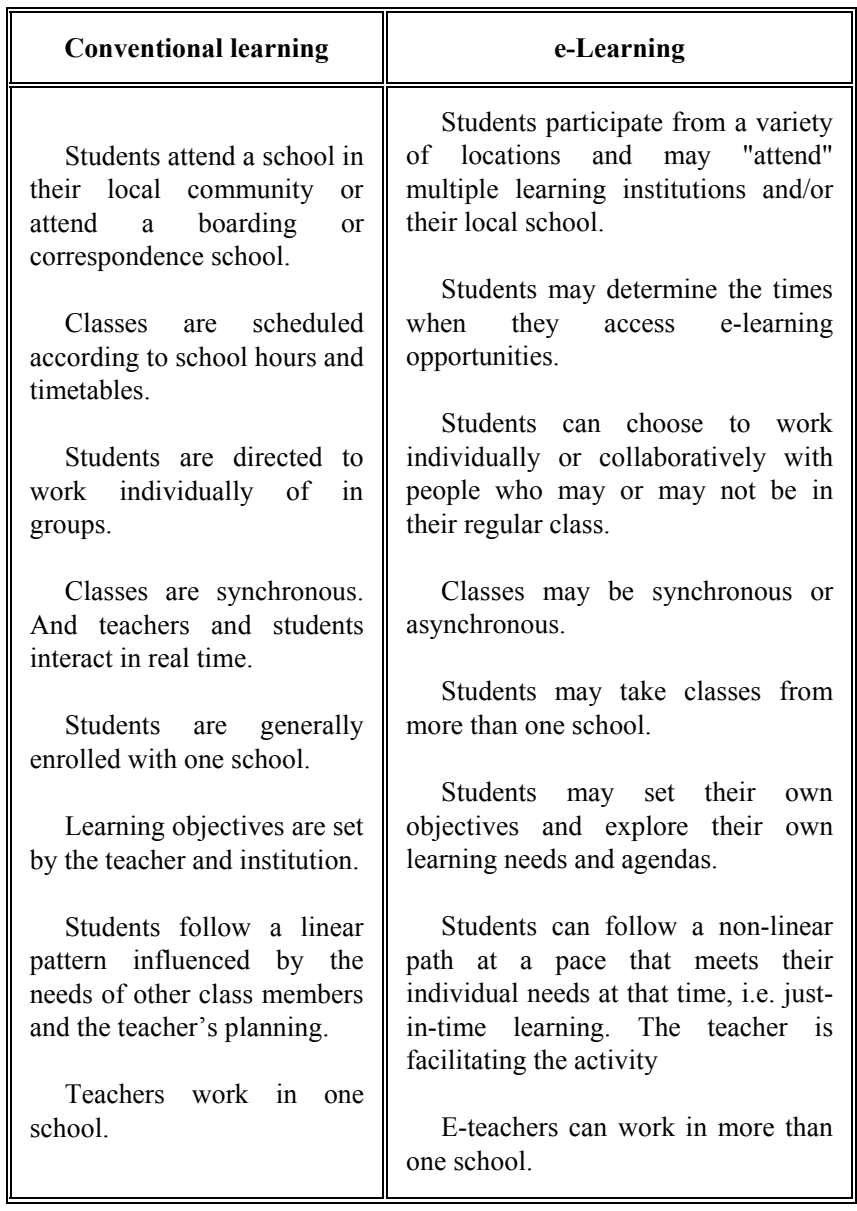

It is important to recognize that while e-learning has much to offer it is not a signal for the end of regular classroom learning as we know it now. Classroom learning will continue to have an important role to play despite the evolution e-learning and e teaching methodology.

\section{Information Technology Learning Modules}

- E-tutoring: The term online tutor includes any person undertaking a role to support and enable students to learn online effectively" (Higgison, 2000).
Communication is an important mainstay of e-tutoring: technology enables people to learn new things because it gives a range of different ways of communicating to students. There is an impressive amount of online resources that enable e-learning, e.g. blog, wiki, social bookmarking, podcasting, audio and video files, interactive games and quizzes, etc.

- Multimedia: the use of several different media (e.g. text, audio, graphics, animation, video, and interactivity) to convey information. Multimedia also refers to the use of computer technology to create, store, and experience multimedia content: hypertext, Computer graphics, Concept maps, Interactive multimedia, Multimedia animation, and Multimedia presentations

- Simulation: Simulation is the imitation of some real thing available, state of affairs, or process. The act of simulating something generally entails representing certain key characteristics or behaviors of a selected physical or abstract system. Simulation is used in many contexts, such as simulation of technology for performance optimization, safety engineering, testing, training, education, and video games. Simulation is also used for scientific modeling of natural systems or human systems in order to gain insight into their functioning. Simulation can be used to show the eventual real effects of alternative conditions and courses of action. Simulation is also used when the real system cannot be engaged, because it may not be accessible, or it may be dangerous or unacceptable to engage, or it is being designed but not yet built, or it may simply not exist.

- Micro worlds: a setting wherein the learner acts; using tools and devices, collecting and interpreting information, interacting perhaps with others, etc. This holds potential because instructional designs have effective instruction towards a degree of student initiative and choice. An environment wherein students are given room to explore and determine goals and learning activities seems an attractive concept. Under this conception, learning is fostered and supported, but not controlled as traditional learning.

\section{J. Research Problem}

Traditional way of learning and development is gradually shifting towards virtual learning. Knowledge realization now a day's business and operational heads of various industries and firms are giving more focus on information technology. It is widely acknowledged by various researches that there is big gap between educations imparted by the educational institutions. Researcher identify the challenges in delivery of the content to students through information technology, which indicates the students competence acquired during their learning and development period from educational institutions, which support them to survive in industry as best performers with absolute contributions. The Government of India (GOI) has been keen to identify the 
issues and challenges by granting various IT enabled projects and training programmes to increase employability in IT industry. Anna University of Technology, Coimbatore Tamil Nadu, India, is effectively implementing the project funds allotted for training of 10,000 IT stream engineering students in the region. In the first phase of the project 5,000 students who were selected from selected institutes are trained and in second phase of the project remaining 5,000 students are been trained.

\section{K. Methodology}

The main objective of the study was to investigate the current state of IT training to students of affiliated institutions. The specific objectives were to assess usage of IT in general by the students, attitudes of students towards the utilization of IT in the provision of student support; the accessibility of ITs that the students would need to utilize in the IT-based student support and factors that would affect the usefulness of IT.

This study employed the survey research method. The questionnaire was made up of four sections - A, B, and C. Section ' $A$ ' dealt with student's usage of ITs, section 'B' determined students attitudes towards ITs while section ' $C$ ' sought their opinion on factors that could affect the use of IT in the Training programme as well as problems encountered by the students due to lack of IT services.

The populations for the study are students from various colleges who have undergone the first phase of IT enabled soft skill training. The students from different technical institutions affiliated to Anna University of Technology, Coimbatore were trained. Technical Institutions/ colleges affiliated to university are geographically distributed in 10 districts. During course of training period the student's email addresses were collected. Within this study, the university provided researcher with the data source. Using this data base the collection of data was done in September 2011. Through simple random sampling 500 students were selected for the study. The respondents received an e-mail with brief information about the survey's objectives and the questionnaire. A total of 60 students $(8.3 \%)$ completed the questionnaire.

\section{Results and Discussion}

\section{1) Usage of IT}

Knowledge of IT was high among all the respondents. In total, (43) $71.6 \%$ of respondents indicated that they know what IT was, while only (17) $28.4 \%$ indicated that they did not know what IT was. In terms of ownership of a personal computer (34) $56.6 \%$ of the respondents indicated that they had personal computers whereas (26) $43.4 \%$ answered 'No' to ownership of a personal computer. This finding is in conformity with Kwapong (2008) who reported that majority of the respondents in her study knew what IT was. Chifwepa (2008) also reported that respondents were aware of IT and that most of them were conversant with word processing.

Thus the study showed that most of the respondents used computers although some of them did not have computers. There is therefore an indication that incorporated of ITs into the training, the students would be able to utilize the facilities especially the computer. Also this would provide a good platform for those who do not have knowledge of using the computer to acquire these skills, improve the attitudes toward the computer, and to computer knowledge and unintentional learning outcomes as reported by Carswell (2000).

\section{2) Mode of Course Delivery}

On the issue of whether students would like to have training to be transmit on Internet, (27) $45 \%$ of the respondents answered yes. However, there were some anxieties that ITs could do away with face-to-face meeting with lecturers hence (33) 55\% of the respondents answered no with reasons such as "we need to see the lecturers, the physical touch is important; we need to ask questions for the lecturers to clarify concepts that we do not understand". This finding is in conformity with Chifwepa (2008), who noted that most of the students indicated that Internet removes the personal touch in contacts and that IT may not be good for asking some questions.

\section{3) Preference of Course Materials}

Respondents were also asked to indicate the formats of course materials they preferred and the reasons for their choices. Most of the respondents (27) $45 \%$ indicated that they preferred the print format of course materials, (20) $33.3 \%$ chose C-D ROM, (13) $21.6 \%$ opted for the Web. The opinions of the respondents on these formats could be explained by the level of ITs they would need in order to utilize the various formats of the materials. The study revealed that those who chose the print format gave reasons such as "the print materials are easily accessible and can be read anywhere, anytime with or without electricity, it does not need equipment and special skills to use it". Others indicated that the print format is cheaper when compared to the other formats. However, some of the respondents also added that sometimes there were delays in the provision of these materials.

The study showed that $35 \%$ of the respondents who opted for the print format were from rural areas; therefore their choice of material might perhaps be attributed to their inability to have access to the equipment needed to utilize the other formats

\section{Conclusion}

Today, active learning is a highly discussed issue since it brings students into the process of their own education taking them beyond the role of passive listener and note taker, and allowing the student to take some direction and initiative in classroom instruction. Web technologies will grow and mature, and learning through the World Wide Web will become increasingly popular. Teachers can distribute lecture notes and other required materials via the Web. Learners then get the opportunity to use learning materials freely and independently, collecting other related materials on the Web as well. When it comes to active learning with audio-visual digital materials, the interaction comes from listening and watching activities, and tools are necessary to enhance the process. One of the major issues in information technology education is the access to and availability of technology. Many institutions are not equipping infrastructure to training large numbers of students with technology. The shift in teaching and learning roles is also an issue in technology education. Teachers have traditionally been sources of information, lecturing and 
providing information for students to internalize and interpret. However, a classroom in which technology is prevalent means that the traditional roles of teacher and student shift.

Using technology effectively requires great support. It requires intensive training as well as in-house technology support. In many situations, institutions can't pay for fulltime tech support, which means that days or weeks can go by before issues are addressed. Without a quick turnaround rate on repairs and installations, technology can be rendered useless pretty quickly. Information technology education is the fact that computers can be very expensive to purchase and maintain. While many instructors may welcome a technology purchase, institutions may not be prepared for the great expense of maintaining and upgrading them as needed. The growth and application of IT in training are the access to the media, its cost effectiveness, its user friendliness and its pedagogic value. Unless all these factors are taken proper care of, growth and application of ITs in Education will continue to be as daunting a task as it ever was.

\section{REFERENCES}

[1] Technology Enhanced Learning: Opportunities for Change. Advance Higher Education in P.S. Goodman (Ed.).pp. 61-74.
[2] M. Alavi, B. Wheeler, and J. Valacich, "Using IT to Reengineer Business Education," An exploratory Investigation to Collaborative Telelearning, MIS Quarterly, September, pp. 294-312, 1995.

[3] M. Alavi, Y. Yoo, and D. Vogel, "Using information technology to add value to management education," Academy of Management Journal, vol. 40, no. 6, pp. 1310- 1333, 1997.

[4] T. Andersen, L. Rourke, D. R. Garrison, and W. Archer, "Assessing teaching presence in a computer conferencing context," Paper presented at the Annual Meeting of the American Educational Research Association, Seattle, WA, 2001.

[5] L. Angus, I. Snyder, and W. Sutherland-Smith, "ICT and educational (dis)advantage: families, computer and contemporary social and educational inequalities," British Journal of Sociology of Education vol. 25 , no. 1, pp. 3-18, 2004.

[6] R. Benbunan-Fich, "Leveraging management education with information technology," In Elsass, P., (Ed.).Proceedings of the Eastern Academy of Management Annual Meeting, May 10-13, Philadelphia, PA. 223-226, 1999.

[7] C. Bouton and R. Y. Garth, "Learning in Groups," San Francisco, CA: Jossey-Bass, Inc.Carswell, L. (2000). Distance education via the Internet: The student experience. British Journal of Educational Technology, vol. 31, no. 1, pp. 29-46, 1983.

[8] J. A. Chambers and J. W. Sprecher, "Computer assisted instruction: Current trends and critical issues," Communications of the ACM, vol. 23, pp. 332-342, 1980.

[9] D. Chatterji, "Strategic impact of the information age," Research Technology Management, vol. 43, no. 1, pp.35-37, 2000.

[10] V. Chifwepa, "Providing Information Communication TechnologyBased Support to Students Case Study of the University Of Zambia," Africa Journal Library Archive Information Science, vol. 18, no. 1, pp. $45-54,2008$.

[11] J. Chizmar and D. Williams, "Altering Time and Space through Network Technologies to Enhance Learning," Cause/Effect, vol. 19, no. 3, pp.14-21, 1996. 